\title{
A regional approach for the influenza surveillance in France
}

\author{
Marc Ruello, Camille Pelat, Céline Caserio-Schönemann, Anne Fouillet*, \\ Isabelle Bonmarin, Daniel Levy-Brühl and Yann Le Strat
}

Santé publique France, Saint-Maurice, France

\section{Objective}

To describe the results of the new organization of influenza surveillance in France, based on a regional approach.

\section{Introduction}

In France, until winter 2014-2015, management and preventive actions for the control of the flu epidemic were implemented when the national incidence of influenza-like illness (ILI) consultations in general practice was over an epidemic threshold. The 2014-2015 influenza epidemic had a major public health impact, particularly in the elderly, and caused a severe overloading of the health care system, in particular emergency departments (ED) [1]. The epidemic alert emitted by the French National Public Health Agency at the national level was too late for the hospitals to prepare themselves in many regions.

After a national feedback organized in April 2015 with all partners involved in influenza surveillance and management, it was recommended to improve influenza surveillance in France following 3 axes: 1) regionalize surveillance so that healthcare structures can adapt to the particular situation of their region; 2) use a pre-epidemic alert level for better anticipating the outbreak; 3) use multiple data sources and multiple outbreak detection methods to strengthen the determination of influenza alert level.

\section{Methods}

A user-friendly web application was developed to provide common data visualizations and statistical results of outbreak detection methods to all the epidemiologists involved in influenza surveillance at the national level or in the 15 regional units of our agency [2]. It relies on 3 data sources, aggregated on a weekly time step: 1) the proportion of ILI among all coded attendances in the ED participating to the OSCOUR Network [3] ; 2) the proportion of ILI among all coded visits made by emergency general practitioners (GPs) working in the SOS Médecins associations [3]; 3) the incidence rate of ILI estimated from a sample of sentinel GPs [4].

For each region each week, 3 statistical outbreak detection methods were applied to the 3 data sources, generating 9 results that were combined to obtain a weekly regional influenza alarm level. Based on this alarm level and on other information (e.g. virological data), the epidemiologists then determined the epidemiological status of each region as either 1) epidemic-free, 2) in pre/post epidemic or 3) epidemic.

The R software was used for programming algorithms and building the web interface (package shiny).

\section{Results}

The epidemiological status of influenza at the regional level was communicated through maps published in the weekly influenza reports of the Agency throughout the surveillance season [5]. In week 2016-W03, Brittany was the first French region to declare the influenza epidemic, with nine other regions in pre-epidemic alert. The epidemic then spread over the whole mainland territory. The peak of the epidemic was declared in week 11, the end in week 16.

\section{Conclusions}

This regional multi-source approach has been made possible by the sharing of data visualizations and statistical results through a web application. This application helped detecting early the epidemic start and allowed a reactive communication with the regional health authorities in charge of the organization of health care, the management and the setting up of the appropriate preventive measures.

\section{Keywords}

Influenza surveillance; R-shiny; SurSaUD; syndromic surveillance; France

\section{Acknowledgments}

The authors thank the emergency departments of the OSCOUR network, SOS Médecins associations, and the Sentinelles network for providing data and for their contribution to the surveillance. The authors also thank the regional SurSaUD team.

\section{References}

[1] Bonmarin I. et al. Influenza activity in mainland France: 2014-15 season. Bull Epidémiol Hebd 2015;32-33.

[2] Pelat C, Bonmarin I, Ruello M. et al. Coordinating regional influenza surveillance through the use of automated outbreak detection methods : the 2015-2016 season in France as illustration. Submitted

[3] Caserio-Schönemann C, Bousquet V, Fouillet A, Henry V. The French syndromic surveillance system SurSaUD (R). Bull Epidémiol Hebd 2014;3-4:38-44.

[4] Valleron AJ, Bouvet E, Garnerin P, Ménarès J, Heard I, Letrait $\mathrm{S}$, Lefaucheux J. A computer network for the surveillance of communicable diseases: the French experiment. Am J Public Health. 1986. 76(11):1289-92[5] http://invs.santepubliquefrance.fr// Dossiers-thematiques/Maladies-infectieuses/Maladies-a-preventionvaccinale/Grippe/Grippe-generalites/Donnees-de-surveillance/ Saison-2015-2016

\section{*Anne Fouillet}

E-mail: a.fouillet@invs.sante.fr 